\title{
An Analysis of the Indexes Effective on the Establishment of Electronic City in Metropolitans (Case Study: Metropolitan Tabriz, Iran)
}

\author{
Rasoul Babanasab (Corresponding Author) \\ Ph.D Student of Geography and Urban Planning, University of Isfahan \\ Isfahan, Iran \\ E-mail: Rasoulbabanasab@yahoo.com \\ Dr. Asghar Zarabi \\ Full Professor of Geography and Urban Planning, University of Isfahan \\ Isfahan, Iran \\ E-mail: a.zarabi@geo.ui.ac.ir \\ Dr. Masoud Taghvaei \\ Full Professor of Geography and Urban Planning, University of Isfahan \\ Isfahan, Iran \\ E-mail: m.taghvaei@geo.ui.ac.ir
}

Received: September 28, 2014 Accepted: October 28, 2014 Published: November 1, 2014

doi:10.5296/ijrd.v1i1.6533

URL: http://dx.doi.org/10.5296/ijrd.v1i1.6533

\begin{abstract}
The current study aims at investigating the indexes effective on the establishment of electronic city (E-city) in the Metropolitan Tabriz. Research type is applied-developmental and dominant approach is descriptive-analytical. To collect data, field and documentary research have been made us of. Based on those procedures, data has been gathered from among specialists of ICT and urban issues working in different organizations of Tabriz through 45 questionnaires. Then, data has been analyzed using SPSS and valuation of
\end{abstract}


variables through Likert Spectrum.

Findings reveal that, in the opinion of the specialists, among 7 indexes studied effective on the establishment of E-cities, management index is on average-to-low level. Total evaluation of indexes using One-Sample T-Test indicates while those indexes are available for the implementation of E-city in the Metropolitan Tabriz, it is possible, to some extent, that citizens perform electronic activities and organizations present electronic services regarding available infrastructures in order to move toward full electronic city. Also, there is significant relationship between the indexes and factors paving the way for the establishment of E-city. And, improving those indexes makes electronic Tabriz more possible in such a manner that management indexes, with correlation coefficient of 0.674 , are the most effective ones among the indexes. Therefore, the first priority in making the metropolitan Tabriz electronic city is the serious attention paid by managers and authorities to new technologies in urban planning, coordination among organizations for decision making and specification of incumbents in implementing E-city.

Keywords: Information and Communications Technology (ICT), Electronic City (E-city), Electronic Services (E-services), Metropolitan Tabriz

\section{Introduction}

Urbanization and focus on cities have increasingly grown so far (Lovehagen \& Bondesson, 2013:175). This trend of urbanization has increased in such a way that it will change the globe into one unified city. However, the consequences of urban life style have made many problems for environment and human beings for years. Those consequences not only have endangered the lives of plants, animals and human beings, but also have pictured an inappropriate future for next generations (Leghayi \& Mohammadzadeh Titkanlu, 1999, p. 33). Based on new ICT approaches, the new age has come up with various solutions for many problems and has been able to help urban communities in this arena (Hataminasab, et al., 2011, p. 2). Cities should be vivid and dynamic. Therefore, one should bear in the mind that cities have sustainable roots. In other words, some theorists have noted that cities could talk with their residents and make speech interactions with their residents (Navabakhsh \& Motlaq, 2009, p. 891).

ICT strategies affect urban environments from land-use patterns to housings and homes (Bishi \& Olajide, 2011, p. 210). Furthermore, they mostly affect on health, governance and security matters of the communities and if their use is properly handled, urban communities will be happy, progressive, salubrious and cooperative and cities will feel alone less than before (Pearson, 2006:3). E-city is not an invention or creative proposal, but it is a reality prevalent according to the needs of people and communities. If such conditions are ignored, the consequences will be costly (Zeynali Azim et al., 2012, p. 6615).

In recent years, many cities have developed thanks to the development of ICT tools. For example, Toronto in Canada, Seoul in South Korea, Singapore, Taiwan and etc have taken important and effective steps in preparing specific conditions and achieving proper experience. 
In Iran, urbanization trend has increasing grown especially in such metropolitans as Tehran, Mashhad, Isfahan, Tabriz and etc. According to 2011 people and housing census in Iran, urbanization rate has reached to $71.4 \%$. Although rapid growth of urbanization and high density of population entail in innovation and rapid economical growth, they produce social, economical and biological challenges in such a way that urban infrastructures grow slower than the rate of people's migration to cities. Those challenges have questioned the dimensions of urban sustainable development; namely, one can point to lack of proportion of city capacity to its residents, heavy congestion of cars in streets, increase in fuel consumption, time waste of citizens in heavy car congestions, change in local biology, air pollution, environment pollution, spread of diseases as result of different pollutions, lack of transparency, less participation of citizens in urban decisions and so on; all and all have made the metropolitan Tabriz face some problems and disorders.

In such conditions, urban planning specialists and theorists believe that E-city establishment is among one of the basic solutions for a way out of those disorders. In such city, many services which people need are available in 24-hour basis. In Iran, although E-city project have been presented for years, it has slowly progressed and organized planning should be done in this regard so that urban managers and citizens cooperatively struggle for proper use of technologies in solving civic challenges and problems. In the metropolitan Tabriz, this goal can be achieved only when E-city expression moves from words toward practice.

\subsection{Research Purposes}

Among most important purposes of the current research is accurate study of effective indexes including literacy, management, investment, ICT specialist human forces, culture, elementary tools and infrastructures and the possibility of E-city establishment regarding those factors.

\subsection{Research Hypotheses}

The present research has investigated following hypotheses:

- It seems that effective factors for the establishment of E-city are not ready in Tabriz.

- It seems that the feasibility of E-city is low in Tabriz regarding available infrastructures in the city.

- There is significant relationship between studied indexes (literacy, management, investment, human forces, access, culture and infrastructure) and the establishment of E-city.

\section{Literature Review and Research Theoretical Foundations}

In a research titled "the impact of information and communication technology on urban and regional planning" Talvitie (2003) proposes that planners should grasp new information, and knowledge as well as new methods and models based on new urban and spatial theories. In a research under the title of "E-government and citizen's engagement with local affairs through e-websites: The case of Spanish municipalities", Cegarra-Navarro et al. (2012) investigate the significance of three types of ICT in exploiting electronic government and developing civil participation. That study has been done on 179 official websites of Spanish municipalities. 
Findings show that ICT implementation not only include a further step taken toward the enhancement of using electronic government service by people, but also provide several opportunities for civil interactions. In an introduction titled "an investigation of ICT role in decreasing inner city trips (case study of Isfahan, Iran), Soltani et al. (2008) put emphasis on the reinforcement of such vital infrastructures as cultural infrastructures in heightening the success of ICT use in Isfahan. In a paper titled "ICT influence on Arak urban development", Motlagh and Behrouznia(2009) recommend such proposals as citizenship training as urban development basics, education of virtual literacy to citizens as the most important goals of network societies, consideration of such points as certification of electronic citizenship as essential proficiencies for citizens, education of electronic citizenship skills to children and youth, reinforcement of citizens' attitude toward ICT, creation of social networks and so on in order to use ICT optimally and improve its effects on urban environments. In a paper titled "an analysis of ICT condition and its role in urban management and planning, case study of Najafabad, Isfahan", Taghvaei et al. (2010) believe that Iranian cities have potential capacity for using ICT and accepting technologies, but need comprehensive plans for proper use of that capacity and the enjoyment of the benefits of ICT depends on the proper coordination of all sectors in urban environments. In his doctoral dissertation, Saberi (2010) investigates urban sustainable development strategies with emphasis on the metropolitan Isfahan's proper governance and smart growth. His findings reveal that its management system has not adapted itself with global measures of proper governance, especially in effectiveness, justice, participation and accountability measures. Furthermore, he emphasizes the establishment of E-cities in recommendations and strategies section.

Several authors have focused on current or future changes resulted from information age or communications revolution and mentioned ICT as the main factor of "death of distance" (Cohen et al., 2002, p. 32). We live in the age of rapid changes moving toward information, knowledge and network societies. E-cities, E-areas and so on are considered as main goals of many countries.

ICT is considered as one of the motors of mentioned technology development. The influence of the development of information communities, especially the impact of ICT on the structure of cities, is a challenge which should be discussed and studied by urban planners in a widespread manner (Talvitie, 2002, p. 5).

In recent decades, E-city concept has been investigated comprehensively and the emergence of such phenomena as smart cards, E-banking, E-education, E-health, E-government and so on results from IT development in all aspects. Regarding new technologies which make social lives more complex, some affairs are easily performed. Furthermore, making use of some aspects of the technology, people are not needed to go to offices personally in order to perform daily tasks. E-city is able to solve such problems as traffic congestion, administrative corruption, social inequalities and so on in real cities (Zeynali Azim et al., 2012, p. 6615). In addition, it helps research for sustainable models for urban development and decrease in the problems and disorders of unsustainable cities (Kotval, 1999, p. 40).

Urban management and planning have locally become significant because of increase in 
urban population and several problems. The main goals of urban management and planning are seen as understanding of urban dynamic procedures and developing effective interventions, resulting in sustainable urban development. Information technology is the only tool able to help achieve those goals. Urban planners and other specialists, involving in urban management and planning in different organizations, should promote IT in order to develop socio-economical and infrastructural conditions for protecting biological benefits. And, ICT should be employed as an important aspect in regional and urban planning. Furthermore, planners should recognize those new needs and challenges. Therefore, ICT has been emerged as the main motor of social and economical development together with several spatial outcomes (Kabir, 2012, p. 169-182).

Couclelis defines E-city as "coordinated and network-based relationships for doing usual tasks of citizens via electronic method, which those tasks had been done personally in common real cities" (Couclelis, 2001). Odendaal believes that E-city is a city in which opportunities created by ICT have been invested on in order to multiply the success and effectiveness of such investments (Odendaal, 2003, p. 586). Therefore, E-city provides the possibility of electronic access of citizens to all offices, inner-city spots and needed different information 24 hours in weekly basis in a stable, reliable, safe and confidential manner (Jalali, 2005, p. 47). It is the best ground for ICT development all over the world. Daily, many people face many problems doing their daily chores in small and large cities. IT bears a significant responsibility in facilitating and accelerating those affairs (Soltani, 2009, p. 26).

The most basic and fundamental activities for creating E-city should be focused on the construction and development of communications infrastructures. An E-city should enjoy communications infrastructures and a proper legal environment so that E-business may be possible in that environment and E-commerce may be implemented. It is essential to establish suitable safety for citizens and regulations proper for E-cities. E-signature, electronic literacy of citizens and so on are among other infrastructures of E-cities for citizens or so-called networkers are considered as vital pillars of E-cities and they should live in such cities. Meanwhile, proper physical texture should be prepared. Also, the other needed infrastructures are active management and true networking culture (Khansari, 2007, p. 35).

E-city's infrastructures include all preparation grounds for such city' elements. Initially, basic and common infrastructures among core elements should be formed. Then, other required sections of implementing applications should be provided according to the plan for developing E-city's elements. Many cities all over the world have developed their infrastructures in the first stage of getting electronic. Those infrastructures consist of four categories: laws and regulations, human forces, culture and social conditions and ICT infrastructures (Jalali, 2005, p. 72).

\section{Research Materials and Methods}

Research type is applied-developmental and its study method is documentary-analytical. Research population consists of ICT and urban specialists in different organizations in the metropolitan Tabriz. For sampling purposes, selective clustering strategies have been employed. To collect data, researcher-made questionnaires, based on the opinions of 45 
specialists in different urban organizations, have been used. To analyze data, SPSS has been used and to answer to research hypotheses, Spearman Test and One-Sample T-Test have been employed. To assess the validity of questionnaires, opinions of theorists and professors in this realm have been made use of. Also, to analyze the reliability of questionnaires' items, Cronbach Alpha coefficient has been employed. Alpha is 0.928 , showing the reliability of the relationship among variables scientifically.

In the study presented here, independent variable is the factors affecting on and paving the way for the establishment of E-city and dependant variable is its possibility in Tabriz. To investigate effective factors, 7 indexes with 25 items have been evaluated and to investigate its possibility as dependent factor, 13 items have been introduces and assessed. All items have been arranged according to Likert Spectrum (so low, low, medium, high and so high).

Table 1. Research indexes and items

\begin{tabular}{|c|c|}
\hline Independent Variables & Items \\
\hline ICT Literacy & $\begin{array}{l}\text { 1. Capability of citizens in using ICT such as } \\
\text { computer, internet, so on } \\
\text { 2. Capability of employees of municipality and } \\
\text { other organizations in using ICT } \\
\text { 3. Proficiency of employees of studied } \\
\text { organization in software and hardware of computer, } \\
\text { and internet. }\end{array}$ \\
\hline Urban Management & $\begin{array}{l}\text { 1. Unified Management in organizations for } \\
\text { making decisions on E-city } \\
\text { 2. Specification of incumbents of E-city } \\
\text { establishment } \\
\text { 3. Inclination of managers toward the } \\
\text { establishment of E-city }\end{array}$ \\
\hline $\begin{array}{l}\text { Investment in } \\
\text { Infrastructures }\end{array}$ & $\begin{array}{l}\text { 1. Public investment in ICT networks and } \\
\text { infrastructures } \\
\text { 2. Private investment in ICT networks and } \\
\text { infrastructures } \\
\text { 3. Investment in studied organizations regarding } \\
\text { hardware and software }\end{array}$ \\
\hline ICT Specialist Human Forces & $\begin{array}{l}\text { 1. ICT specialist human forces in city e-service } \\
\text { centers } \\
\text { 2. ICT specialist human forces in city offices and } \\
\text { organizations }\end{array}$ \\
\hline ICT Culture & $\begin{array}{l}\text { 1. Motivation and desire of citizens for performing } \\
\text { electronic activities }\end{array}$ \\
\hline
\end{tabular}




\begin{tabular}{|c|c|}
\hline & $\begin{array}{l}\text { 2. Culture of using Internet and ICT among citizens } \\
\text { 3. Culture of using Internet and ICT among offices } \\
\text { and organizations }\end{array}$ \\
\hline Access to E-Service Centers & $\begin{array}{l}\text { 1. Coffee Nets } \\
\text { 2. ATMs } \\
\text { 3. E-service Centers } \\
\text { 4. Government Counters } \\
\text { 5. Police E-Service Centers }\end{array}$ \\
\hline ICT Infrastructure and Tools & $\begin{array}{l}\text { 1. Costs of Wireless, Dial up and ADSL internet for } \\
\text { citizens } \\
\text { 2. Internet speed } \\
\text { 3. Systems on offices and organizations for } \\
\text { accountability to citizens } \\
\text { 4. Proportion of computers to household } \\
\text { concerning their needs } \\
\text { 5. Availability of computers in studied } \\
\text { organizations } \\
6 \text { Availability of scanners and printers in studied } \\
\text { organizations }\end{array}$ \\
\hline dependent Variable & Items \\
\hline $\begin{array}{l}\text { The Possibility of Making Electronic } \\
\text { Every Activity for Establishing } \\
\text { E-City }\end{array}$ & $\begin{array}{l}\text { 1. Bank Activities } \\
\text { 2. Administrative matters } \\
\text { 3. Business } \\
\text { 4. Logistics } \\
\text { 5. Leisure } \\
\text { 6. Education } \\
\text { 7. Travel } \\
\text { 8. Job-Seeking } \\
\text { 9. Medical Treatment } \\
\text { 10. Decision Making } \\
\text { 11. Scientific } \\
\text { 12. Information Research } \\
\text { 13. Municipality Services }\end{array}$ \\
\hline
\end{tabular}




\section{Research Discussion and Findings}

In the current research, studied area is the metropolitan Tabriz. It is the capital of East Azerbaijan Province in Iran. This city is the largest one in Northwestern Iran and Azerbaijani-residing regions and is recognized as administrative, communicational, commercial, political, industrial and military pole of the region. Its area is 24451 hectares and its population was 1378935 in 2006 and reached to 1494998 in 2011(www.tabriz.ir). According to East Azerbaijan Telecommunications Company, till the end of 2013, network externality coefficient of land phone, mobile phone and internet had ascendant trend. Furthermore, network externality coefficient of land phone was $46.43 \%$, mobile phone $123.8 \%$ and internet $35.85 \%$. In terms of E-service centers and offices, the data regarding governments' front counters and rural ICT offices has been provided: Till the end of 2013, 111 governments' front counters and 27 rural ICT offices were delivering E-services in different parts of Tabriz. Also, till the end of 2013, there were 633 public payphones in different districts if Tabriz (East Azerbaijan Telecommunication Company, 2013). According to 2011 Iranian people and housings census, among total 453886 households living in Tabriz, 196625 households had personal computers.

In order to develop Tabriz facing several urban challenges, urban managers and planners attempts at reducing urban problems for citizens through the establishment of E-city and the deliverance of E-services. Of course, Tabriz has been a pioneer in most of the fields and the investigation of Tabriz Telecommunication Company, Municipality and Municipality's Statistics and IT Department shows if coordinated and organized operational plans are observed with proper road maps, the first Iranian E-city would be established in Tabriz. Of the effective steps taken in this regard include setting up a datacenter as the Municipality's commands room, developing exclusive optical fiber for the Municipality, running several information portals and websites, carrying out three stages of E-citizen project aiming at enhancing citizens' E-literacy level, opening E-citizen club, issuing identification E-cards for citizens, planning for setting up 500 websites within Tabriz Municipality Complex, designing the most equipped and largest city portal in Iran, installing the Municipality's exclusive radio mast, carrying out networking master plan in Tabriz Municipality Complex, running up systems for delivering electronic services in housing development affairs and issuing building permit in all districts of the Municipality, designing Tabriz search software, establishing a system for recommendations, designing inner-city transportation supervision smart system, setting up tolls E-payment system, drawing new tourism map for Tabriz, designing the Municipality's master system of auctions and bids and opening the Municipality's call center.

Regarding the significant of E-cities in developing urban societies and sustainable urban development and to investigate and determine current condition of Tabriz in terms of factors effective on E-cities and their implementation, researcher-made questionnaires have been distributed among 45 ICT and urban affairs specialists selected from different organization and gathered data has been analyzed by SPSS. Analytical and descriptive findings are as follows:

The distribution of respondents with respect to gender revels that among 45 respondents, 33 
are male, that is, $73.3 \%$ and 12 are men, that is, $26.7 \%$. The evaluation of the respondents' education level shows that 17 respondents have bachelor's degree, that is, 37.8\%, 23 have Master's degree, that is, $51.1 \%$ and 5 have $\mathrm{Ph} . \mathrm{D}$, that is, $11.1 \%$. Also, regarding average use of internet by respondents in weekly basis, $15.6 \%$ of respondents use internet lower than 5 hours, $24.4 \% 5$ to 10 hours, $20 \% 11$ to 15 hours, $8.9 \% 16$ to 20 hours and $31.1 \%$ over 20 hours.

\subsection{Research Hypotheses Test}

4.1.1 Hypothesis 1: It seems that effective factors for the establishment of E-city are not ready in Tabriz

To assess the current condition of indexes effective in E-city establishment, One-Sample T-Test is employed. Using this test, this hypothesis is investigated as follows:

As shown in Table 2, P-value is higher than 0.05 in all indexes except for management one. Therefore, it can be deducted that population mean among indexes, other than management one, is equal to test value and zero hypothesis, that is, mean should be 3 in all indexes other than management one, is accepted.

Regarding all indexes, as all indexes population mean is 3.05 and P-value is higher than 0.05 and upper limit of confidence interval is positive, it can be said that effective factors for the establishment of E-city in Tabriz are ready to some extent.

Table 2. Investigation of factors effective on the establishment of E-city in Tabriz

\begin{tabular}{|c|c|c|c|c|c|c|c|c|}
\hline \multicolumn{9}{|c|}{ One-Sample T-Test } \\
\hline \multicolumn{9}{|l|}{ Test Value $=3$} \\
\hline \multirow{2}{*}{$\begin{array}{l}\text { Factors Effective } \\
\text { on the } \\
\text { Establishment of } \\
\text { E-city in Tabriz }\end{array}$} & \multirow[t]{2}{*}{ Mean } & \multirow[t]{2}{*}{$\begin{array}{l}\text { Std. } \\
\text { Deviation }\end{array}$} & \multirow[t]{2}{*}{$\mathrm{t}$} & \multirow[t]{2}{*}{ df } & \multirow[t]{2}{*}{$\begin{array}{l}\text { Sig. } \\
\text { (2-tailed) }\end{array}$} & \multirow[t]{2}{*}{$\begin{array}{l}\text { Mean } \\
\text { Difference }\end{array}$} & \multicolumn{2}{|c|}{$\begin{array}{l}95 \% \text { Confidence } \\
\text { Interval of the } \\
\text { Difference }\end{array}$} \\
\hline & & & & & & & Lower & Upper \\
\hline Literacy & 3.1407 & 0.60923 & 1.550 & 44 & .128 & .14074 & -.0423 & .3238 \\
\hline Management & 2.7852 & 0.68223 & -2.112 & 44 & .040 & -.21481 & -.4198 & -.0099 \\
\hline Investment & 3.0074 & 0.62559 & .079 & 44 & .937 & .00741 & -.1805 & .1954 \\
\hline $\begin{array}{r}\text { Specialist Human } \\
\text { Forces }\end{array}$ & 3.1111 & 0.87833 & .849 & 44 & .401 & .11111 & -.1528 & .3750 \\
\hline Culture & 3.1481 & 0.69470 & 1.431 & 44 & .160 & .14815 & -.0606 & .3569 \\
\hline
\end{tabular}




\begin{tabular}{|r|l|l|l|l|l|l|l|l|}
\hline Access & 3.1289 & 0.73997 & 1.168 & 44 & .249 & .12889 & -.0934 & .3512 \\
\hline Infrastructure & 3.0556 & 0.58387 & .638 & 44 & .527 & .05556 & -.1199 & .2310 \\
\hline $\begin{array}{r}\text { All Factors or } \\
\text { Indexes }\end{array}$ & 3.0539 & 0.44370 & .814 & 44 & .420 & .05386 & -.0794 & .1872 \\
\hline
\end{tabular}

4.1.2 Hypothesis 2: It seems that the feasibility of E-city is low in Tabriz regarding available infrastructures in the city

To assess the current condition of indexes effective in E-city establishment, One-Sample T-Test is employed. Using this test, this hypothesis is investigated as follows:

As shown in Table 3, P-value is higher than 0.05 in all indexes except for management one. Therefore, it can be deducted that population mean among indexes, other than management one, is equal to test value and zero hypothesis, that is, mean should be 3 in all indexes other than management one, is accepted.

Regarding all indexes, as all indexes population mean is 3.0085 and P-value is higher than 0.05 and upper limit of confidence interval is positive, it can be said that effective factors for the establishment of E-city in Tabriz are ready to some extent.

Table 3. The investigation of possibility of E-City establishment according to specialists

\begin{tabular}{|c|c|c|c|c|c|c|c|c|}
\hline \multicolumn{9}{|c|}{ One-Sample T-Test } \\
\hline \multicolumn{9}{|l|}{ Test Value $=3$} \\
\hline \multirow{3}{*}{$\begin{array}{l}\text { Possibility of } \\
\text { E-City } \\
\text { Establishment } \\
\text { Regarding } \\
\text { Available } \\
\text { Infrastructures }\end{array}$} & \multirow[t]{2}{*}{ Mean } & \multirow[t]{2}{*}{$\begin{array}{l}\text { Std. } \\
\text { Deviatio } \\
\mathrm{n}\end{array}$} & \multirow[t]{2}{*}{$\mathrm{t}$} & \multirow[t]{2}{*}{ df } & \multirow[t]{2}{*}{$\begin{array}{l}\text { Sig. } \\
\text { (2-tail } \\
\text { ed) }\end{array}$} & \multirow[t]{2}{*}{$\begin{array}{l}\text { Mean } \\
\text { Differenc } \\
\text { e }\end{array}$} & \multicolumn{2}{|c|}{$\begin{array}{l}95 \% \\
\text { Confidence } \\
\text { Interval of the } \\
\text { Difference }\end{array}$} \\
\hline & & & & & & & Lower & Upper \\
\hline & 3.0085 & 0.71697 & .080 & 44 & .937 & .00855 & -.2069 & .2239 \\
\hline
\end{tabular}

4.1.3 Hypothesis 3: There is significant relationship between studied indexes (literacy, management, investment, human forces, access, culture and infrastructure) and the establishment of E-city

To investigate the relationships among factors effective on the establishment of E-city, Spearman Test is employed. As shown in Table 4, there is a positive significant relationship between mentioned indexes and the establishment of E-city in such a manner that P-values of all indexes are higher than 0.05 , showing significant relationship, meaning that the higher the 
indexes effective on the establishment of E-city, the higher the possibility of the establishment of E-city in Tabriz.

Table 4. The Relationship between Effective Indexes and Possibility of E-City Establishment Based on Spearman Test

\begin{tabular}{|r|r|r|r|}
\hline Index & $\begin{array}{l}\text { Correlation } \\
\text { Coefficient }\end{array}$ & Sig. (2-tailed) & Relationship \\
\hline Literacy & 0.457 & 0.002 & Positive \\
\hline Management & 0.674 & 0.000 & Positive \\
\hline Investment & 0.638 & 0.000 & Positive \\
\hline Specialist Human Forces & 0.409 & 0.005 & Positive \\
\hline Culture & 0.532 & 0.000 & Positive \\
\hline Access & 0.670 & 0.000 & Positive \\
\hline Infrastructure & 0.569 & 0.000 & Positive \\
\hline
\end{tabular}

\section{Conclusions and Research Recommendations}

The concept of electronic city has been firstly introduced in 2000 in Iran. In Iranian metropolitans, respective authorities have begun moving toward becoming electronic. However, obviously, none of those activities in the process of getting electronic has not implemented based on global criteria and principals in this regard so far. Therefore, practical measures should be taken concerning this issue. Although the development of ICT in Tabriz is not in the accepted global levels, what its authorities have done in recent years has paved the way for ICT development to some extent. In the present study, it is attempted at investigating the factors effective on the establishment of electronic cities as well as the possibility of its establishment in Tabriz in the viewpoints of 45 ICT and urban affairs specialists. Findings indicate that effective factors for the establishment of E-city in Tabriz are ready to some extent. Also, there is a positive significant relationship between mentioned indexes and the establishment of E-city, meaning that the higher the indexes effective on the establishment of E-city, the higher the possibility of the establishment of E-city in Tabriz.

According to the findings, moving toward the optimal use of ICT and the establishment of an electronic city, some recommendations may be presented as follows:

- Taking comprehensive, real and organized measures as the most important step of ICT development;

- Exploiting the experience of successful states in the establishment of E-cities; 
- Using available ICT facilities in optimal and systematic ways;

- Allocating enough budget to ICT development in order to reinforce telecommunication infrastructures;

- Producing training programs for promoting the benefits of electronic cities among citizens and urban authorities;

- Paying attention to unified urban management and the improvement of inter-organizational affiliations in order to benefit more from the merits of electronic cities;

- Training public and private employees to update themselves regarding informing online visitors and users truly;

- Developing fast and economic wide-band network;

- Planning for assigning necessary facilities to citizens in order to enjoying minimum resources such as PCs;

- Training virtual literacy to citizens and allocating financial facilities in order to promote electronic citizenship;

- Increasing net cafes, e-service centers, ICT offices, e-banks, catalogs, banners and billboards, and urban advertisement televisions in order to promote performing civic affairs electronically;

- Running social networks such as chat rooms among urban districts in order to enhance participation and unity of citizens and give recommendations and complaints about urban projects, the performance of the authorities and so on.

\section{References}

Bishi, H., \& Olajide, O. (2011). Effects of Information Technology Facilities on the Urban Environment: A Comparative Study of Lagos Island and Victoria Island, Lagos.

Cegarra-Navarro, J. G., Pachon, J. R. C., \& Cegarra, J. L. M. (2012). E-government and citizen's engagement with local affairs through e-websites: The case of Spanish municipalities. International Journal of Information Management, 32(5), 469-478. http://dx.doi.org/10.1016/j.ijinfomgt.2012.02.008

Cohen, G., Salomon, I., \& Nijkamp, P. (2002). Information-communications technologies (ICT) and transport: does knowledge underpin policy? Telecommunications Policy, 26, 31-52. http://dx.doi.org/10.1016/S0308-5961(01)00052-0

Couclelis, H. (2001). The Social Construction of Digital City. USA: University of California press.

Hataminasab, S. H., Taleifar, R., Asgharinejad, M., \& Dehghani, A. (2011). An Evaluation of Managers' Viewpoints on Electronic Cities (Case Study: Yazd Electronic City, Iran). Business Management Researches Quarterly, 3(5), 1-26.

Iran Statistics Center. (2011). Results of 2011 Iranian Housing and People Census. Tehran, Iran.

Jalali, A. A. (2005). Electronic City. Iran University of Science and Technology Publications, 
Iran.

Khansari, K. (2007). Current Citizen, Future Networker. ICT Use Development Monthly, 5(2), $34-40$.

Kotval, Z. (1999). Telecommunications, A realistic strategy for the revitalization of American Cities. Cities, 16(1), 33-41. http://dx.doi.org/10.1016/S0264-2751(98)00052-3

Leghayi, H. A., \& Mohammad zadeh Titkanlu, H. (1999). An Introduction of Urban Sustainable Development Concept and Urban Planning Role. Fine Arts Quarterly, 6, 32-42.

Lovehagen, N., \& Bondesson, A. (2013). Evaluating sustainability of using ICT solutions in smart cities - methodology requirements. Proceedings of the First International Conference on Information and Communication Technologies for Sustainability, ETH Zurich.

Motlagh, M., \& Behrouznia, P. (2009). An Investigation of ICT Influences on the Development of Cities (Case Study: Arak, Iran). Social Sciences Research Journal, 3(2), $7-38$.

Navabakhsh, M., \& Motlagh, M. (2009). Effects of Urban Information and Communication Technology on Sustainable Development. Journal of Food, Agriculture \& Environment, 7(3\&4), 891-897.

Odendaal, N. (2003). Information and Communication Technology and Local overnance: Understanding the Difference between Cities in Developed and Emerging Economies. Computers, Environment and Urban Systems, 27, 585-607. http://dx.doi.org/10.1016/S0198-9715(03)00016-4

Pearson, I. (2006). The role of future ICT in city development. Foresight, 8(3), 3-16. http://dx.doi.org/10.1108/14636680610668036

Rasel Kabir, M. (2012). Towards Digital Bangladesh: Scope of ICT integrated Urban Planning and Management. Journal of Bangladesh Institute of Planners, 5, 169-183.

Saberi, H. (2010). Urban Sustainable Development Strategies with Emphasis on Proper Governance and Smart Growth (Case Study: Isfahan, Iran). Thesis of Geography Department, Isfahan University, Iran.

Soltani, L., Zarabi, A., \& Zangiabadi, A. (2008). An Investigation of ICT Role in Reducing Requests of Inner-City Trips (Case Study: Isfahan, Iran). Isfahan University's Humanities Research Journal, 32(4), 1-18.

Soltani, M. (2009). Spatial Analysis of ICT Role in the Development of Electronic Tourism in Isfahan, Iran. MA Thesis of Geography Department, Isfahan University, Iran.

Taghvaei, M., Babanasab, R., \& Mousavi, S. C. (2010), An Analysis of ICT Condition and Its Role in Urban management and Planning (Case Study: Nadjafabad, Iran). Tabriz University's Geography and Planning Journal, 15(31), 25-49.

Talvitie, J. (2002). The Influence of Information Technology on Spatial Development. FIG 


\section{Macrothink}

XXII International Congress, Washington, D.C. USA.

Talvitie, J. (2003). The Impact of Information And Communication Technology on Urban and Regional Planning. Kiinteistoopin ja talousoikeuden julkaisuja, Espoo 2003, Helsinki University of Technology Department of Surveying Institute of Real Estate Studies.

Zeynali Azim, A., Behnud, E., Zeynali, M., \& kasiri, S. (2012). Electronic city: A City of Today and Tomorrow. Journal of Basic and Applied Scientific Research, J. Basic. Appl. Sci. Res., 2(7), 6615-6621.

\section{Copyright Disclaimer}

Copyright for this article is retained by the author(s), with first publication rights granted to the journal.

This is an open-access article distributed under the terms and conditions of the Creative Commons Attribution license (http://creativecommons.org/licenses/by/3.0/). 